\title{
Improving Germination Rate of the Florida Legume Galac- tia elliottii
}

\author{
J.P. MUIR AND W.D. PITMAN
}

Abstract

The perennial legume, Galactia elliottï Nuttal, is widely distributed in the Spodosol soils (fiatwoods) of the Southeastern United States and could have potential as a component of plant mixtures for revegetating deteriorated flatwoods rangeland and other disturbed sites. Seeds of this lezume were collected from a peninsular Florida fatwoods site as they developed during the fall of 1983. Since a range in seed development was obtained, seeds were grouped according to maturity and fill. Seed treatments as well as seed development effects on germination were evaluated. Seed treatment by seed development interactions were obtained $(P<$ 0.05 ) indicating that seed of the 3 development groups (mature full seed, mature partially filled seed, and green seed) responded differently to the seed treatments. Mechanical scarification with sandpaper and treatment with sulfuric acid effectively increased $(P<0.05)$ both total germination and rate of germination compared to the untreated control for the 2 mature seed groups. Mechanical scarification and sulfuric acid treatment also increased rate of germination of green seed. However, final (day 52) total sermination of sandpaper-scarified ereen seed did not differ $(P>0.05)$ from the control. Hot water treatment was effective in increasing total germination of green seed but did not produce a response $(P<0.05)$ until after the first week of incubation. Mature seeds from a number of sites were collected in the winter of 1986-87 and composited for germination studies. Sandpaper scarification, sulfuric acid, and a control were evaluated. Initial germination of $84 \%$ for sandpaper-scarified seeds from this trial was greater than germination of similar seeds from 1983, while sulfuric acid-treated seeds did not germinate as well. Effectiveness of mechanical seed coat disruption at increasing germination of mature seed indicates that the primary limitation to germination of mature seed of this legume is seed coat impermeability. Differential responses among seed of differing development indicates that seed fill occurred in the green seed before complete development of seed coat impermeability, thus, allowing less severe treatments than seed coat disruption to affect germination.

Key Words: seed treatments, germination, legumes

The flatwoods rangeland which extends from peninsular Florida along the coastline of the Southeastern United States is characterized by soils of low fertility and native grasses of low forage quality. Numerous native legumes are distributed throughout this area. However, natural stands of most native legumes are sparse with little benefit from nitrogen fixation or forage quality currently being obtained. There is a need to evaluate the potential of reestablishing selected native legumes on deteriorated rangelands and to determine their value for revegetation of other disturbed sites.

Galactia elliottii Nuttal (commonly known as milk pea) is a viney, herbaceous legume which occurs naturally throughout South Carolina, Georgia, and Florida (Radford et al. 1968). Sparse stands occur where some protection from excessive grazing has been provided and $G$. elliottii can even be found growing in ungrazed bahiagrass (Paspalum notatum Flugge.) plantings.

\footnotetext{
Authors are graduate student, Agronomy Department, University of Florida, Gainesville 32611 and associate professor, Agricultural Research and Education Center, Ona 33865.

This article is Florida Agr. Exp. Sta. Paper No. 7728.

Manuscript accepted 7 April 1987.
}

In concurrence with the results of Cushwa et al. (1968) with Galactia volubilis (L.) Britton, preliminary germination trials indicated that $G$. elliottii seeds exhibited strong dormancy or hardseededness ( $7 \%$ germination in 14 days). Studies were initiated to evaluate the effects of seed development and selected seed treatments on germination of $G$. elliottii.

\section{Materials and Methods}

\section{Experiment I}

Seeds of $G$. elliottii were hand-picked from a flatwoods range site at the Agricultural Research and Education Center at Ona, Fla., during the fall of 1983. Since flowering occurred over an extended time period and predation and seed shatter were hazards, all pods which were either full or dry were picked as they were encountered. This resulted in ranges in seed fill and maturity of the harvested seeds. Seeds were grouped into 3 categories to assess the effect of these developmental differences on germination. Groups were comprised of either mature full seeds (maturity indicated by dark brown coloration), mature partially filled seeds (seeds which appeared to be physiologically mature but not completely filled), and green seeds (seeds which were picked after seed fill but before complete maturation).

Seed treatments consisted of the following: (1) mechanical disruption of the seed coat by sandpaper abrasion, (2) immersion in 18 mol liter ${ }^{-1} \mathrm{H}_{2} \mathrm{SO}_{4}$ for 30 seconds, (3) immersion in $75^{\circ} \mathrm{C}$ water for 5 minutes, (4) exposure to $80^{\circ} \mathrm{C}$ water vapor for 5 minutes, (5) germination in $0.3 \mathrm{~mol} \mathrm{liter}^{-1} \mathrm{KNO}_{3}$ as described by the Association of Official Seed Analysts (1949), and (6) an untreated control germinated in distilled water.

A factorial arrangement of treatments consisting of 3 seed development groups, 6 seed treatments, and 5 replications resulted in 90 experimental units in a randomized complete block design. Blocks were arranged by height within the germinator. Each experimental unit consisted of 10 seeds with number of seeds per experimental unit limited to restrict cross-contamination of seed by fungi during the extended germination period. Number of replications was limited by the seed quantity available. Seeds were treated and placed in individual, sterilized petri dishes containing moistureretaining paper liners. Paper liners in the petri dishes were kept moist throughout the germination period. Germination trials were conducted in a controlled environment germinator with 12-hour light and dark cycles at a constant temperature of $25^{\circ} \mathrm{C}$.

Germination counts were made $2,4,7,14,21,28,35$, and 52 days after initiation of the germination trial. Germination was defined as the development of both a functional radical and at least 1 cotyledon (Association of Official Seed Analysts, 1949). Germination percentages were transformed for analysis (arcsine of square root of percent germination $\times 0.01$ ) with the original data presented in the text and tables.

\section{Experiment II}

The 1983 seed collection was an opportunistic harvest from a sparse naturally occurring stand which has not been observed to produce such a heavy seed crop in other years. Thus, during the winter of 1986-87 seeds were collected from a number of sites in the central Florida area including the site collected in 1983. Few seeds were found per plant, and essentially all seeds obtained were full, mature seeds which were composited for germination evaluations. 
Germination procedures were similar to those used previously except that only 1 seed development group was used, and only sand paper scarification, sulfuric acid, and a control treatment were applied.

Seed numbers and number of replications were the same as those used in Experiment I. A completely randomized design was used, with data transformed for analysis as described previously. Again, original data are presented in the text and table. This germination trial was monitored for $\mathbf{4}$ weeks, with germination levels evaluated on days $4,7,14,21$, and 28 .

\section{Results and Discussion}

\section{Experiment I}

Germination began on day 4 , after which germination differed among treatments throughout the experiment. Since seed treatment by development interactions occurred $(P<0.05)$ on day 14 and thereafter, simple effects rather than main effects are presented (Table 1). Blocks (trays within the germinator) did not affect

Table 1. Mean cumulative germination of Galactia elliotti following varlous treatments of seed grouped according to seed development.

\begin{tabular}{|c|c|c|c|c|c|c|}
\hline \multirow{2}{*}{$\begin{array}{l}\text { Germi- } \\
\text { nation } \\
\text { period }\end{array}$} & \multicolumn{6}{|c|}{ Seed treatment } \\
\hline & $\begin{array}{l}\text { Sand- } \\
\text { paper }\end{array}$ & $\mathrm{H}_{2} \mathrm{SO}_{4}$ & $\begin{array}{c}\text { Hot } \\
\text { water }\end{array}$ & $\begin{array}{l}\text { Water } \\
\text { vapor }\end{array}$ & $\mathrm{KNO}_{3}$ & Control \\
\hline \multirow[t]{2}{*}{ days } & \multirow{2}{*}{\multicolumn{6}{|c|}{ Mature full seed }} \\
\hline & & & & & & \\
\hline \multirow[t]{2}{*}{$\begin{array}{r}4 \\
7 \\
14 \\
28 \\
52\end{array}$} & $\begin{array}{l}28 a^{1} \\
68 a \\
80 a \\
88 a \\
92 a\end{array}$ & $\begin{array}{l}12 \mathrm{~b} \\
46 \mathrm{~b} \\
66 \mathrm{a} \\
76 \mathrm{a} \\
78 \mathrm{ab}\end{array}$ & $\begin{array}{l}2 c \\
6 c \\
16 b c \\
40 b \\
62 c\end{array}$ & $\begin{array}{c}0 c \\
4 c \\
20 b \\
42 b \\
70 b c\end{array}$ & $\begin{array}{l}0 \mathrm{c} \\
2 \mathrm{c} \\
4 \mathrm{~cd} \\
6 \mathrm{c} \\
12 \mathrm{~d}\end{array}$ & $\begin{array}{r}0 \mathrm{c} \\
2 \mathrm{c} \\
2 \mathrm{~d} \\
8 \mathrm{c} \\
18 \mathrm{~d}\end{array}$ \\
\hline & \multicolumn{6}{|c|}{ Mature partially-filled seed } \\
\hline $\begin{array}{r}4 \\
7 \\
14 \\
28 \\
52\end{array}$ & $\begin{array}{l}34 a \\
58 a \\
70 a \\
86 a \\
86 a\end{array}$ & $\begin{array}{l}10 b \\
34 b \\
52 b \\
62 b \\
66 b\end{array}$ & $\begin{array}{l}4 c \\
8 c \\
22 \mathrm{~cd} \\
48 \mathrm{~b} \\
64 \mathrm{~b}\end{array}$ & $\begin{array}{r}0 c \\
4 c \\
28 c \\
48 b \\
62 b\end{array}$ & $\begin{array}{r}4 c \\
8 c \\
12 d \\
18 c \\
36 c\end{array}$ & $\begin{array}{r}0 \mathrm{c} \\
0 \mathrm{c} \\
2 \mathrm{~d} \\
12 \mathrm{c} \\
26 \mathrm{c}\end{array}$ \\
\hline \multicolumn{7}{|c|}{ Green seed } \\
\hline $\begin{array}{r}4 \\
7 \\
14 \\
28 \\
52\end{array}$ & $\begin{array}{l}32 \mathrm{a} \\
56 \mathrm{a} \\
62 \mathrm{a} \\
64 \mathrm{ab} \\
66 \mathrm{ab}\end{array}$ & $\begin{array}{l}10 \mathrm{~b} \\
38 \mathrm{~b} \\
66 \mathrm{a} \\
76 \mathrm{a} \\
78 \mathrm{a}\end{array}$ & $\begin{array}{l}4 c \\
14 c \\
60 a \\
74 a \\
80 a\end{array}$ & $\begin{array}{l}0 \mathrm{c} \\
6 \mathrm{c} \\
16 \mathrm{~b} \\
36 \mathrm{c} \\
36 \mathrm{c}\end{array}$ & $\begin{array}{l}4 c \\
8 c \\
30 \mathrm{~b} \\
46 \mathrm{bc} \\
62 \mathrm{ab}\end{array}$ & $\begin{array}{l}0 c \\
8 c \\
16 b \\
34 c \\
58 b\end{array}$ \\
\hline
\end{tabular}

IMeans within each line not followed by the same letter differ $(P<0.05)$ according to Duncan's Multiple Range Test.

germination throughout the experiment.

On days 4 and 7 , seed treatment by development interactions were not significant $(P>0.10)$, thus results of the various seed treatments were the same for all 3 seed development groups. Ger- mination was highest $(P<0.05)$ for sandpaper-scarified seed on these 2 dates (31\% and $61 \%$ on days 4 and 7 , respectively). Sulfuric acid treatment also resulted in greater $(P<0.05)$ germination $(11 \%$ and $39 \%$ on days 4 and 7 , respectively) than the other treatments which were similar (2\% and $6 \%$ average germination on days 4 and 7 , respectively).

Germination levels on day 14 and thereafter were greater $(P<0.05)$ for sandpaper-scarified and sulfuric acid treated seed than for the control with all seed development groups. The hot water and water vapor treatments were less consistent (Table 1) but were generally superior to the control and $\mathrm{KNO}_{3}$ treatments on the mature seed groups. The $75^{\circ} \mathrm{C}$ water treatment was as effective in increasing germination of green seed after day 14 as either sandpaper or sulfuric acid. Similar results with hot water treatment of Desmanthus velutinus Scheele seeds were reported by Haferkamp et al. (1984) They obtained slower germination rates and comparable total germination percentages for hot water treated seeds compared to mechanical scarification and sulfuric acid treatment. However, the $80^{\circ} \mathrm{C}$ water vapor treatment failed to improve the germination of green seeds and even resulted in lower final germination than the control.

Seeds remaining at the end of the germination period were classified as either deteriorated seed or hardseed. Seed treatment by seed development interactions were again obtained, thus, simple effects were evaluated (Table 2). All seeds in the sandpaper scarification and sulfuric acid treatments had either germinated or deteriorated by the end of the germination period. Substantial amounts of hardseed remained in the $\mathrm{KNO}_{3}$ and control treatments of mature full seed. A majority of the green seeds receiving the water vapor treatment deteriorated. Seed development had a major impact on hardseed content of untreated seeds at the end of the germination period with all 3 groups differing $(P<0.05)$ from each other. Hardseed content $(74 \%)$ of untreated mature full seeds would allow an extended period for germination to occur while the low hardseed content (12\%) of the green seeds would provide little opportunity for plant establishment beyond the season of seeding. Hardseed content of mature incompletely filled seeds was intermediate between levels of mature full and green seeds. Seed scarification generally did not result in increased $(P>0.05)$ seed deterioration. Two exceptions were the $64 \%$ deteriorated seed of water vapor treated green seed versus $30 \%$ deteriorated seed for the control and $22 \%$ deteriorated seed of sulfuric acid treated full mature seed versus $8 \%$ for the control. Mature, completely filled seeds either mechanically scarified or untreated did not deteriorate to the extent that comparably treated incompletely filled or green seeds did.

In order to evaluate treatment effects on germination rate, the number of days to $50 \%$ germination was evaluated. Again, significant interactions were obtained, and simple effects are presented (Table 3). As indicated by germination percentages at the successive evaluation dates, both sandpaper scarification and sulfuric

Table 2. Deterionted seed and hariseed of Galactia elliottï after a 52-day sermination period as afiected by seed treatment and development.

\begin{tabular}{|c|c|c|c|c|c|c|}
\hline \multirow[b]{2}{*}{ Seed development } & \multicolumn{6}{|c|}{ Seed treatment } \\
\hline & Sand paper & $\mathrm{H}_{2} \mathrm{SO}_{4}$ & Hot water & Water vapor & $\mathrm{KNO}_{3}$ & Control \\
\hline & \multicolumn{6}{|c|}{ Deteriorated Seed } \\
\hline \multirow[t]{2}{*}{$\begin{array}{l}\text { Mature full seed } \\
\text { Partially-filled seed } \\
\text { Green seed }\end{array}$} & $\begin{array}{l}8 b^{\prime} \\
14 c^{\prime} \\
34 b^{2}\end{array}$ & $\begin{array}{l}22 \mathrm{a} \\
34 \mathrm{a} \\
22 \mathrm{~cd}\end{array}$ & $\begin{array}{r}8 b \\
4 d \\
20 d\end{array}$ & $\begin{array}{c}4 \mathrm{~b} \\
22 \mathrm{bc} \\
64 \mathrm{a}\end{array}$ & $\begin{array}{l}10 \mathrm{~b} \\
26 \mathrm{ab} \\
24 \mathrm{~cd}\end{array}$ & $\begin{array}{c}8 \mathrm{~b} \\
26 \mathrm{ab} \\
30 \mathrm{bc}\end{array}$ \\
\hline & \multicolumn{6}{|c|}{ Hardseed } \\
\hline $\begin{array}{l}\text { Mature full seed } \\
\text { Partially-filled seed } \\
\text { Green seed }\end{array}$ & $\begin{array}{l}0 \mathrm{c} \\
0 \mathrm{~d} \\
\mathbf{O} \mathrm{b}\end{array}$ & $\begin{array}{l}0 \mathrm{c} \\
0 \mathrm{~d} \\
0 \mathrm{~b}\end{array}$ & $\begin{array}{r}30 \mathrm{~b} \\
32 \mathrm{~b} \\
0 \mathrm{~b}\end{array}$ & $\begin{array}{c}26 \mathrm{~b} \\
16 \mathrm{c} \\
0 \mathrm{~b}\end{array}$ & $\begin{array}{l}78 a \\
38 \mathrm{ab} \\
14 \mathrm{a}\end{array}$ & $\begin{array}{l}74 a \\
48 a \\
12 a\end{array}$ \\
\hline
\end{tabular}

IMeans within each line not followed by the same letter differ $(P<0.05)$ according to Duncan's Multiple Range Test. 
Table 3. Days to $50 \%$ germination of Galactia elliottil seed as affected by seed treatment and development.

\begin{tabular}{|c|c|c|c|c|c|c|}
\hline \multirow[b]{2}{*}{ Seed development } & \multicolumn{6}{|c|}{ Seed treatment } \\
\hline & Sandpaper & $\mathrm{H}_{2} \mathrm{SO}_{4}$ & Hot water & Water vapor & $\mathrm{KNO}_{3}$ & Control \\
\hline $\begin{array}{l}\text { Mature full seed } \\
\text { Partially-filled seed } \\
\text { Green seed }\end{array}$ & $\begin{array}{l}6.4 \mathrm{~d}^{1} \\
7.8 \mathrm{~d} \\
7.0 \mathrm{~d}\end{array}$ & $\begin{array}{c}9.8 \mathrm{~d} \\
15.4 \mathrm{c} \\
12.6 \mathrm{~cd}\end{array}$ & $\begin{array}{l}44.8 \mathrm{~d} \\
32.6 \mathrm{~b} \\
15.4 \mathrm{c}\end{array}$ & $\begin{array}{r}33.6 \mathrm{c} \\
38.8 \mathrm{~b} \\
>52.0 \mathrm{a}\end{array}$ & $\begin{array}{r}>52.0 \mathrm{a} \\
>52.0 \mathrm{a} \\
33.2 \mathrm{~b}\end{array}$ & $\begin{array}{r}>52.0 \mathrm{a} \\
>52.0 \mathrm{a} \\
45.0 \mathrm{a}\end{array}$ \\
\hline
\end{tabular}

'Means within each line not followed by the same letter differ $(P<0.05)$ according to Duncan's Multiple Range Test.

acid treatment resulted in more rapid germination than the control for each seed development group. More rapid germination was also generally obtained with hot water and water vapor treatments than with the control. The only exception was water vapor treatment of green seeds, which resulted in a high level of deteriorated (fungi-destroyed) seeds. Also of interest is the germination rate of green seeds subjected to the hot water treatment, which was more rapid $(P<0.05)$ than untreated seed but not as rapid as sandpaper scarified seed.

To insure that mechanical scarification was similar among seed development groups, seeds were individually hand scarified with sandpaper and visually inspected before use. Thus, means of germination of sandpaper-treated seeds for the 3 seed groups reflect properties of the seed rather than susceptibility of the seed or seed coat to mechanical disruption. The higher germination of sandpaperscarified seeds than that of sulfuric acid-treated seeds at 4 and 7 days indicates that less disruption of the seed coat may have been obtained with the 30-second exposure to concentrated sulfuric acid. However, a subsequent evaluation of a range of exposure times to sulfuric acid produced no differences in germination over a range of exposure times for 30 seconds to 12 minutes. Even the 30 -second sulfuric acid treatment may have resulted in damage to some seed or increased susceptibility to fungal deterioration.

\section{Experiment II}

Sandpaper-scarified seeds germinated rapidly with $84 \%$ germination by day 4 . Although this was a considerably higher germination level at the first count than obtained for seeds of similar development in Experiment I, the final total germination of these seeds was not greater (Table 4). In fact, all sandpaper-scarified

Table 4. Mean cumulative germination of fully-developed Galactia elliotti seeds collected from a number of sites in central Florida during the winter of 1986-87.

\begin{tabular}{lccc}
\hline \hline Germination period & Sandpaper & $\mathrm{H}_{2} \mathrm{SO}_{4}$ & Control \\
\hline days & $84 \mathrm{a}$ & $2 \mathrm{~b}$ & $0 \mathrm{~b}$ \\
4 & $84 \mathrm{a}$ & $6 \mathrm{~b}$ & $0 \mathrm{~b}$ \\
7 & $84 \mathrm{a}$ & $10 \mathrm{~b}$ & $0 \mathrm{~b}$ \\
14 & $84 \mathrm{a}$ & $18 \mathrm{~b}$ & $0 \mathrm{c}$ \\
28 & & & \\
\hline
\end{tabular}

'Means within each line not followed by the same letter differ $(P<0.05)$ according to Duncan's Multiple Range Test.

seeds that did not germinate during the first 4 days of this experiment had deteriorated by the end of the second week of the germination trial resulting in $16 \%$ deteriorated seeds. Deterioration percentages of sulfuric acid-treated and control seeds at day 28

iJ.P. Muir 1985. Evaluation of the native Florida legume Galactia elliottii for forage use: seed scarification, shade tolerance and Rhizobium inoculation. MS Thesis. Univ. of Florida, Gainesville. were 2 and $4 \%$, respectively. Most seeds of these 2 treatments were visually unaffected during the germination period with 80 and $96 \%$ hardseed for sulfuric acid-treated and control seeds, respectively.

Germination was low for both sulfuric acid-treated seeds and untreated seeds. The low germination of sulfuric acid-treated seeds in this experiment compared to Experiment I may reflect both characteristics of the seeds and inadvertent differences in treatment application. Failure of control seeds to germinate in this 28-day period does not represent a substantial difference from the $8 \%$ germination of control seeds in Experiment $I$.

\section{Summary and Conclusions}

Seed harvests of $G$. elliottii from stands managed for seed production would generally be expected to include a mixture of mature and green seeds since flowering is indeterminate resulting in seed set over an extended time period, and danger of seed loss precludes delayed harvest. Seed fill is determined primarily by number of pods per plant and environmental conditions affecting photosynthesis during the period of seed filling. The data indicate that mechanical scarification would be the superior seed treatment to enhance early germination of all seed development groups. Sulfuric acid treatment also provides an alternative method of increasing germination, although the treatment used in this evaluation was inconsistent. For seed lots with a large proportion of green seeds, hot water treatment could be used effectively to enhance germination. This treatment could be especially useful when other scarification treatments are not available and germination over a 6 to 8 week period is desired because of potential for erratic rainfall. In situations where seed scarification will not be utilized, a high proportion of green seeds provides an opportunity for better shortterm germination levels than do seed lots of predominately mature seeds with the accompanying disadvantage of lower hardseed content for later germination.

Since germination of $G$. elliottii was increased by treatments which disrupted the seed coat and hardseededness was greater in seeds which were allowed to attain full physiological maturity before harvest, hardseededness in this species appears to be the result of physical seed coat impermeability requiring an afterripening maturation period for complete development.

\section{Literature Cited}

Association of Orficial Seed Analysts. 1949. Rules for testing seed. Proc. Ass. Off. Seed. Anal., Corvallis, Ore.

Cushwa, C.T., R.E. Martin, and R.L. Miller. 1968. The effects of fire on seed germination. J. Range Manage. 21:250-254.

Haferkamp, M.R., D.C. Klasock, and R.D. Webater. 1984. Impact of presowing seed treatments, temperature and seed coats on germination of velvet bundleflower. J. Range Manage. 37:185-188.

Radford, A.E., H.E. Ahles, and C.R. Bell. 1968. Manual of the vascular flora of the Carolinas. Univ. North Carolina Press. Chapel Hill, N.C. 